\title{
Clay particles as binder for earth buildings materials: a fresh look into rheology of dense clay suspensions
}

\author{
Gnanli Landrou ${ }^{1, *}$, Coralie Brumaud ${ }^{1}$, and Guillaume Habert ${ }^{1}$ \\ ${ }^{1}$ Chair of Sustainable Construction, Civil Engineering Department, ETH Zürich-8093 Zürich, Switzerland
}

\begin{abstract}
In the ceramic industry and in many sectors, clay minerals are widely used. In earthen construction technique, clay plays a crucial role in the processing. The purpose of this research is to understand and modify the clay properties in earth material to propose an innovative strategy to develop a castable earth-based material. To do so, we focused on the modification of clay properties at fresh state with inorganic additives. As the rheological behaviour of clays is controlled by their surface charge, the addition of phosphate anion allows discussing deep the rheology of concentrated clay suspensions. We highlighted the thixotropic and shear thickening behaviour of a dispersed kaolinite clay suspensions. Indeed, by adding sodium hexametaphosphate the workability of clay paste increases and the behaviour is stable during time after a certain shear is applied. Moreover, we stress that the aging and the shift in critical strain in clay system are due to the re-arrangement of clay suspension and a decrease of deformation during time. The understanding of both effect: thixotropy and aging are crucial for better processing of clay-based material and for self-compacting clay concrete. Yet, studies need to pursue to better understand the mechanism.
\end{abstract}

\section{Introduction}

In the ceramic industry and in many sectors clay minerals are widely used and of importance to the processing [1]. In earthen construction, clay acts like binder for earth as it displays colloidal interactions and adhesion forces between fine sand and grains [2]. While extensive researches exist on clay dispersion [3, 4]; few researches applied the knowledge on earth building material. However due to the current environmental challenges buildings with earth regains interest as it is fully recyclable, is adaptable in most climates and societies; and it has the lowest environmental impact with respect to cement $[5,6]$. Howbeit, its development is hindered by the time and cost required for current earth construction techniques [7].

The objective of this study is therefore to transform earthen architecture by providing a material that is as easy and as cheap to use as current concrete products thanks to novel technologies borrowed to science and technology of cement and concrete. This mean investigates the influence of additive as sodium hexametaphosphate on clay in order to improve the workability of the earth-based material

To do so, a careful control of the rheology of the clays requires a better understanding of colloidal interactions between particles and knowledge transfer from the fundamental physics of grain and colloidal interactions to the civil engineering $[8,9]$.

As unique binder in earth, clay; negatively charged particle; can have its surface interaction changed with the help of dispersants coming from cement and ceramic industries. Among dispersants commonly used in ceramic processing, sodium phosphate is known to guarantee an efficient dispersion of natural clay materials [10, 11]. However, the rheological behavior access so far for dispersed clay suspensions are difficult to transpose in earth.

Even though several studies have been done on the influence of sodium hexametaphosphate (NaHMP) on concentrated clay suspensions, the stability and control of behaviour of concentrated clays suspensions when additives are introduced [11-15], few studies explain the effect of time and the thixotropic effect due to the percentage of dispersant added with respect to viscoelastic properties of clays.

In this paper, we focus on the modification of clay properties with inorganic additive in order to deflocculate the clay during the casting process. While doing so, we highlight the ability of sodium phosphate to fluidify the earth material by reducing the yield stress. Moreover, we stress the thixotropic behaviour of dispersed clay through the adsorption of phosphate on the positive edge and the stability of the suspension during time. Furthermore, we show that during time the re-organization of clay particles can allow a phase transition from dispersed particles to agglomerate while keep the reversibility of the system.

\section{Experimental observations}

The clay used is a kaolin FP80 powder supplied from Alberto Luisoni AG, Switzerland. The characteristics of kaolin FP80 is reported in table 1. The XRD measurement reveals that more than $87 \%$ of kaolin FP80

* Corresponding author: glandrou@ethz.ch 
is kaolinite clay; specifically, non-swelling clay minerals.

Table 1: The physical characteristics of kaolin FP80.

\begin{tabular}{|c|c|c|}
\hline $\begin{array}{c}\text { specific surface } \\
\text { area SSA } \\
\left(\mathrm{m}^{2} . \mathrm{g}^{-1}\right)\end{array}$ & $\begin{array}{c}\text { mean diameter } \\
(\mu \mathrm{m})\end{array}$ & $\begin{array}{c}\text { density } \\
\left(\mathrm{g} . \mathrm{cm}^{-3}\right)\end{array}$ \\
\hline 9.10 & 8.69 & 2.62 \\
\hline
\end{tabular}

All rheological measurements were performed on dispersed clay pastes. The ratio water to clay was kept constant $(\mathrm{W} / \mathrm{C}=0.69)$ and the amount of dispersant sodium hexametaphosphate (NaHMP) was kept at $0.2 \mathrm{wt} \%$ with respect to the amount of solid.

\subsection{Thixotropy and shear thickening}

To study the influence NaHMP and to investigate it stability during time on concentrated kaolinite paste, we conducted at room temperature $\left(23 \pm 0.1^{\circ} \mathrm{C}\right)$ rheological measurements. The sequence used for yield stress measurement comprise the following steps: first, we applied an increasing shear rate ramp from $0.1 \mathrm{~s}^{-1}$ to 300 $\mathrm{s}^{-1}$ (with a logarithmic distribution of shear rate) for $300 \mathrm{~s}$ followed by a decreasing shear ramp from $300 \mathrm{~s}^{-1}$ to 0.1 $\mathrm{s}^{-1}$ for $300 \mathrm{~s}$. The yield stress of the reference mixture $(\mathrm{W} / \mathrm{C}=0.69)$ is $1000 \mathrm{~Pa}$ and an addition of $0.2 \mathrm{wt} \%$ NaHMP, reduce considerably the yield stress.

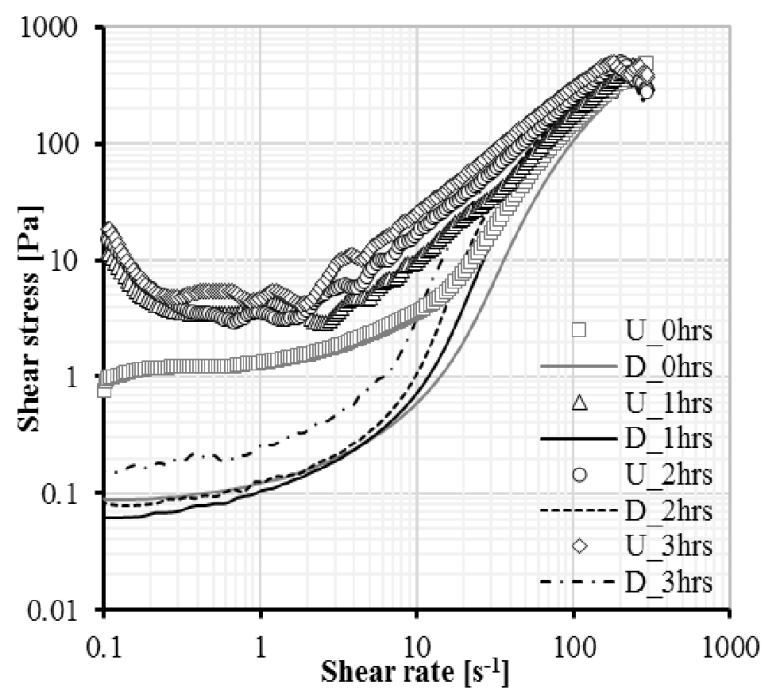

Figure 1: Flow curve of kaolinite $(\mathrm{W} / \mathrm{C}=0.69)+0.2 \% \mathrm{NaHMP}$, evolution of shear stress as a function of shear rate during time. $\mathrm{U}$ represents ramp up and $\mathrm{D}$ ramp down.

Figure 1 illustrates the evolution of shear stress versus shear rate measured every one hour for a suspension of kaolinite dispersed with $0.2 \mathrm{wt} \%$ NaHMP. The yield stress determined from ramp down fluctuate in the same range which means that the structural change is reversible when a sufficient shear rate is applied. Besides the static stress determined from the ramp up after one hour resting time is $10 \mathrm{~Pa}$. The increase of static stress measured at low shear rate $\left(0.1 \mathrm{~s}^{-1}\right)$ from $t_{0}$ to $t_{1}$ suggest a reorganization between clay particles and formation of new interaction forces during time. Additionally, we observed that for constant rest time, the same static stress is measured. The results confirm the reversible behaviour mentioned above and as the process is repeatable. We suggested that at high volume fraction and when dispersed, clay suspensions display thixotropic behaviour. It means clay particles, at rest, have time to re-organize and re-structure due to Brownian motion. Moreover, zeta potential measurement showed a partial coverage $(0.2 \mathrm{wt} \% \mathrm{NaHMP})$ of clay edge charge. Then the presence of residual positive charge induces weak Van der Walls attractive forces. This behaviour typical of thixotropic fluid is discussed for others colloidal system $[16,17]$. The dispersion mentioned is due to the adsorption of phosphate ions at the edge of the clay which result on the increase of negative surface charge of clay particles [14] and the increase of electrostatic repulsion forces.

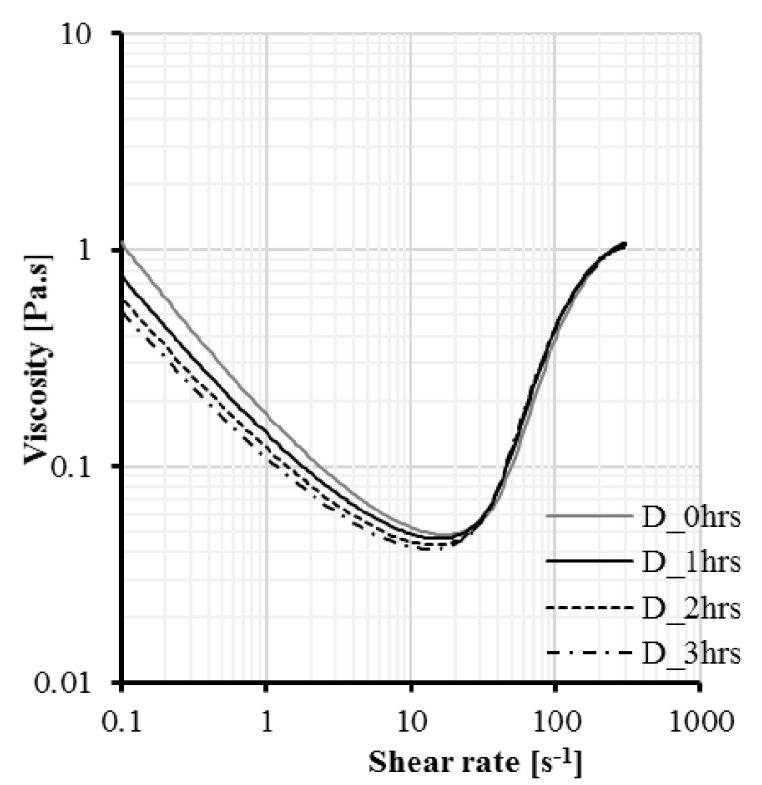

Figure 2: Flow curve of kaolinite $(\mathrm{W} / \mathrm{C}=0.69)+0.2 \% \mathrm{NaHMP}$, evolution of viscosity as a function of shear rate during time. D represents the ramp down.

Furthermore, we observe in figure 2 that dense and dispersed clay suspension displays a shear thickening behaviour as at shear rate above $10 \mathrm{~s}^{-1}$ the viscosity increases. Without dispersant, shear thinning behaviour is observed. We assume that the surface chemistry of clay, the orientation of clay particles affect the transition from shear thinning to shear thickening. As the shear thickening behaviour is inexistence without dispersant, we concluded that the shear thickening is hidden by a yield stress and it can be recovered with appearance of a threshold yield stress as shown in [18]. Besides, previous studies showed that this phenomenon depends on the shape of particles and the volume fraction [19], so further experiments are ongoing to understand the driven 
mechanism and the influence of volume fraction and shape.

Yet we suggest in our case that the onset of shear thickening is linked to change in the microstructure of the suspension. At low shear, the clay particles are orientated parallel into layer which facilitate the flow of colloid then at high shear, the suspensions organized into clusters jam due to the percolation of clusters This suggest a hydrodynamic interaction between dispersed clay clusters formed at high shear. Similar observation is discussed in [20] as the authors stress on the effect of surface chemistry on the shear thickening.

\subsection{Aging: phase transition}

To understand the aging process of dispersed kaolinite clay suspension, we carried out vane test measurement in order to identify the deformation range and transition from liquid dispersed to liquid agglomerated.

Yet, to study the aging behaviour, to determine the interaction range, to classify the microstructure change during time and cover flow onset no matter the critical strain, a compromise was however to be reached between the duration of the test and its accuracy. It was not possible to apply a constant shear rate to measure all the strain and so we developed the following protocol. The sequence starts with an initial pre-shear at $100 \mathrm{~s}^{-1}$ during 30 s to ensure that all the samples were in the same state of stress and strain, followed by different waiting time $(0,0.5,2,6$ and $12 \mathrm{hrs})$. Then a constant shear rate of $10^{-3} \mathrm{~s}^{-1}$ was applied during $50 \mathrm{~s}$ followed by a logarithmic increase of shear rate from $10^{-3}$ to $0.5^{*} 10^{-}$ ${ }^{3} \mathrm{~s}^{-1}$ during 10s. A constant shear rate of $0.005 \mathrm{~s}^{-1}$ was finally applied during $16 \mathrm{~min}$ to determine late the flow onset and late deformation.

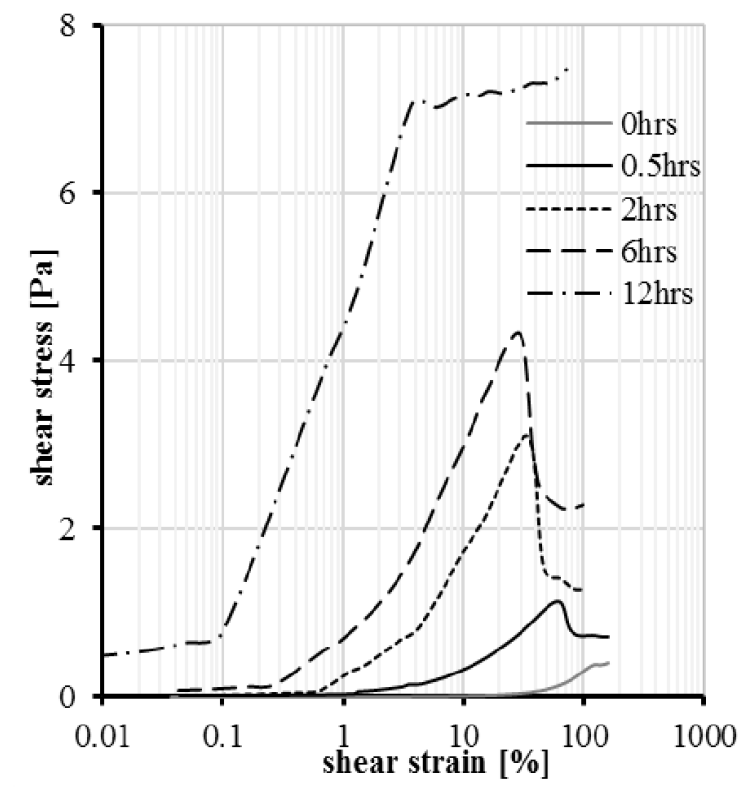

Figure 3: Evolution of shear stress as a function of shear strain for a mixture of $35.4 \%$ kaolinite $+0.2 \mathrm{wt} \%$ NaHMP. Vane test measurements carried out at different waiting time.
In figure 3, we reported the evolution of shear stress as a function of strain for a mixtures of kaolinite paste $(\mathrm{W} / \mathrm{C}=0.69)$ dispersed with $0.2 \mathrm{wt} \%$ of NaHMP. The measurements are performed at different resting time. We can observe that at $t_{0}$, right after mixing, the strain is above $100 \%$ and the static stress is lower than $1 \mathrm{~Pa}$ meaning that the material is fluid, deformable and the distance of interaction is considered as long range. It is suggested that the clay interaction forces are controlled by face (-) / face (-) and face (-) / edge (-). Moreover, during time the critical strain decreases while the static stress increases so we can propose that the aging allow the agglomeration of clay particles and the rigidification of colloidal network. The shift in strain and the increase of static stress confirm the reorganization of clay particles driving by Brownian motion and the existence of few positive charges. This enables the agglomeration. Similar behaviour are observed in colloidal gel and mentioned in [21, 22]. The authors describe the phenomenon as glass-glass transition during aging of colloidal clay. The transition from long range interaction due to the presence of dispersant to short range colloidal interaction between clay particles but with lower stress in comparison to reference paste is still unclear however, we should keep in mind that the agglomeration is reversible and the kinetics of agglomeration is dependent of the percentage of dispersant introduce.

\section{Discussions}

In the present studies, the samples are covered during the experiments to avoid effect of evaporation. The results obtained from Fig 1 and 2 show that the NaHMP activity is stable during time which highlight the robustness and efficiency of the dispersant. Moreover, we can observe that when deflocculate, the clay particles are nonorganized and are randomly assembled with weak attractive forces which explain the low yield stress and higher critical strain, above $100 \%$ deformation at $\mathrm{t}_{0} \mathrm{Fig}$ 3. However, during time the increase of static stress determine at flow onset and the decrease of shear strain suggests a change in the microstructure. Indeed, the samples microstructure become more structured and ordered Fig 3.

These findings point out that there are microstructural change or reaction occurring during time when the reference paste is deflocculated. This observation appears odd as the sample still fluid after 6 hours as shown in Fig 1. The increase of shear stress is then associated to aging and new interaction between deflocculate clay platelets face (-) / (-) face, or face (-) / (-) edge) and face (-) / (+) edge.

Yet, the shift in strain suggests the formation of soft clusters or agglomerate easily breakable at higher shear stress. In fact, as reported in Fig 1, we observed that the waiting time increases the shear stress from $0.1 \mathrm{~Pa}$ to $10 \mathrm{~Pa}$ and the process is reversible. The hypothesis of formation of cluster and agglomerate seems to support the shear thickening behaviour but more analysis need to be done to confirm the origin of shear thickening. 


\section{Conclusion}

We have conducted extensive experimental studies in order to get insight on the rheological behaviour of dispersed kaolinite clay and the stability of NaHMP. The results reveals that NaHMP is robust, efficient and stable dispersant during time. More we highlight the thixotropic behaviour and rigidification of the system with time due to the different type of interaction in clay (face-face or face-edge).

Besides, the findings reveal that the aging and the rearrangement of clays particles are responsible to the net increase of inter-particles forces with a decrease of critical strain during. However, further works are undergoing to understand the shear thickening behaviour.

The authors would like to acknowledge the Swiss National Science Foundation (SNSF) for it financial support.

\section{References}

1. F. Bergaya,G. Lagaly, Handbook of clay science 5. (2013)

2. D. Gelard, L. Fontaine, S. Maximilien, C. Olagnon, J. Laurent, H. Houben, H. Van Damme, Proceedings of the International Symposium on Earthen Structures. IIS Bangalore, (2007)

3. J. L. Amorós, V. Beltrán, V. Sanz, J. C. Jarque, Appl. Clay Sci., 49, 33 (2010)

4. P.-I. Au,Y.-K. Leong, Colloids Surf. A: Physicochem. Eng. Asp., 436, 530 (2013)

5. J.-C. Morel, A. Pkla, P. Walker, Constr. Build. Mater., 21, 303 (2007)

6. A. Shukla, G. N. Tiwari, M. S. Sodha, Renew. Energy., 34, 755 (2009)

7. R. F. Anger, Laetitia, Bâtir en terre: du grain de sable à l'architecture (2009)

8. K. Kovler,N. Roussel, Cem. Concr. Res., 41, 775 (2011)

9. J. Yammine, M. Chaouche, M. Guerinet, M. Moranville, N. Roussel, Cem. Concr. Res., 38, 890 (2008)

10. F. Andreola, E. Castellini, J. M. F. Ferreira, S. Olhero, M. Romagnoli, Appl. Clay Sci., 31, 56 (2006)

11. F. Andreola, E. Castellini, G. Lusvardi, L. Menabue, M. Romagnoli, Appl. Clay Sci., 36, 271 (2007)

12. E. Castellini, R. Andreoli, G. Malavasi, A. Pedone, Colloids Surf. A: Physicochem. Eng. Asp., 329, 31 (2008)

13. E. Castellini, C. Berthold, D. Malferrari, F. Bernini, Appl. Clay Sci., 83-84, 162 (2013)

14. G. Landrou, C. Brumaud, F. Winnefeld, R. Flatt, G. Habert, Materials, 9, 330 (2016)

15. A. Perrot, D. Rangeard, A. Levigneur, Mater. Struct., 1 (2016)

16. J. Mewis,N. J. Wagner, Adv. Colloid Interface Sci., 147-148, 214 (2009)
17. N. Roussel, G. Ovarlez, S. Garrault, C. Brumaud, Cem. Concr. Res., 42, 148 (2012)

18. E. Brown, N. A. Forman, C. S. Orellana, H. Zhang, B. W. Maynor, D. E. Betts, J. M. DeSimone, H. M. Jaeger, Nat Mater, 9, 220 (2010)

19. H. A. Barnes, J. Rheol., 33, 329 (1989)

20. W. Yang, Y. Wu, X. Pei, F. Zhou, Q. Xue, Langmuir, (2017)

21. R. Angelini, E. Zaccarelli, F. A. de Melo Marques, M. Sztucki, A. Fluerasu, G. Ruocco, B. Ruzicka, Nat. Commun., 5, (2014)

22. E. Zaccarelli, Journal of Physics: Condensed Matter, 19, 323101 (2007) 